\title{
Close encounters of the worst kind: reforms needed to curb coral reef damage by recreational divers
}

\author{
Bing $\operatorname{Lin}^{1}$ (1)
}

Received: 22 January 2021 / Accepted: 30 June 2021 / Published online: 16 July 2021

(C) The Author(s) 2021

\begin{abstract}
Intentional and unintentional physical contact between scuba divers and the seabed is made by most divers and multiple times per dive, which often results in damage to corals and other marine life. Current efforts to reduce reef contacts (e.g., voluntary dive operator recognition programs and voluntary dive standards) can be effective, but lack sufficient incentive structures for longterm compliance. In their current capacity, these programs fail to reduce reef contacts to tolerable levels. Regulatory policies can facilitate pervasive and permanent shifts in human behavior, but have been underutilized to change unsustainable underwater norms. Most coral reefs open to recreational diving lie within territorial waters of individual countries, and many already have existing forms of protection with legislation that can be easily modified. Successful policy precedents in Marine Protected Areas (e.g., bans on underwater glove use) and elsewhere (e.g., antismoking laws in public spaces and legislation enforcing seat belt use) demonstrate the largely untapped potential of using effective governance to change destructive diving norms for good. To reduce intentional reef contacts, policy-makers can enact regulations in MPAs directly banning all contact between divers and the seabed. To reduce $u n$ intentional contacts, policy-makers can create policy safeguards that preempt such occurrences (e.g., requiring divers to keep a certain distance from the seabed). Crucially, such policies will need accompanying formal and
\end{abstract}

Topic Editor Anastazia Teresa Banaszak

Bing Lin

blin@ princeton.edu

1 Program in Science, Technology, and Environmental Policy, School of Public and International Affairs, Princeton University, Princeton, NJ 08544, USA informal enforcement measures that are equitable, effective, and efficient to motivate compliance and effect lasting behavior change. Having a robust, well-enforced, regulatory framework to tackle both types of reef contacts lends credence to the efforts of existing conservation programs, and is key to permanently changing divers' underwater attitudes and fostering sustainable scuba diving behavior to the benefit of all.

Keyword Scuba diving - Diver damage - Coral reef . Social norm change $\cdot$ Marine protected area $\cdot$ Tourism policy

\section{Diver-reef contacts in context}

Coral reefs are inordinately important to marine biodiversity and humans (Moberg and Folke 1999; Spalding et al. 2017), yet are on a steep global decline (Bellwood et al. 2004; Hoegh-Guldberg et al. 2007; Halpern et al. 2008). Concurrently, recreational scuba diving has become a multi-billion-dollar industry (Ong and Musa 2011), with over a million new divers gaining certification each year (PADI 2019). Despite its non-extractive nature, recreational diving can still adversely affect reef ecosystems, both directly and indirectly. Direct effects involve intentional and inadvertent damage to corals and other marine life (Hawkins and Roberts 1992; Tratalos and Austin 2001; Hasler and Ott 2008; Giglio et al. 2017, 2020; CeruttiPereyra et al. 2021). Indirect impacts associated with higher diving pressures include sediment deposition from fin kicks (Zakai and Chadwick-Furman 2002), elevated rates of coral disease (Lamb et al. 2014), and shifts in ecosystem dominance and structure (Hawkins et al. 1999). 
Scuba divers can directly damage reef life through physical contact between any part of their bodies or diving equipment and the seabed; these are called reef contacts (Zakai and Chadwick-Furman 2002). Reef contacts can be intentional, usually from reef-holding for support or out of apparent curiosity for handling and examining wildlife (Camp and Fraser 2012), or unintentional, often from a lack of situational awareness, care, or underwater buoyancy control while diving (Worachananant et al. 2008; Chung et al. 2013; Toyoshima and Nadaoka 2015; Roche et al. 2016). Studies find that between 71 and 98 percent of all scuba divers make (intentional or unintentional) reef contact at least once every dive (Krieger and Chadwick 2013; Toyoshima and Nadaoka 2015), with an average reef contact rate for divers ranging from 0.2 to over 4.0 reef contacts per minute of diving (Harriott et al. 1997; Medio et al. 1997). Of such contacts, over a quarter can cause visible damage to corals or other marine life (Chung et al. 2013; Roche et al. 2016). Further, because reef contacts might also include impacts with non-living components of the seabed (e.g., dead coral or rubble), reef contacts directly involving live coral have even higher rates of damage (up to $74 \%$ of contact instances in one study; Krieger and Chadwick 2013), especially with respect to branching corals (Rouphael and Inglis 1997; Zakai and Chadwick-Furman 2002).

High reef contact rates pervade even among divers with advanced certifications or high experience levels, putting reefs at risk of damaging contacts from divers of all levels of expertise (Barker and Roberts 2004; Di Franco et al. 2009; Camp and Fraser 2012; Chung et al. 2013; Roche et al. 2016). Reef contacts also have widespread geographic documentation, including in Australia (Harriott et al. 1997; Rouphael and Inglis 1997), Hong Kong (Chung et al. 2013), Israel (Zakai and Chadwick-Furman 2002), Italy (Di Franco et al. 2009), Japan (Toyoshima and Nadaoka 2015), Mexico (Gil et al. 2015; Cerutti-Pereyra et al. 2021), the Philippines (Roche et al. 2016), Spain (Luna et al. 2009), St. Lucia (Barker and Roberts 2004), Thailand (Worachananant et al. 2008), and the USA (Camp and Fraser 2012; Krieger and Chadwick 2013). When reef contacts and their associated damages to marine life are compounded across millions of divers every year, multiple times a dive, and all over the world, the cause for conservation concern becomes clear.

\section{Existing efforts lack resolve}

Several programs and initiatives have tried to reduce divers' reef contact rates, sometimes successfully and sometimes not. The most coordinated approach, voluntary dive operator recognition programs, involves granting individual dive centers "eco-certifications" when they choose to adhere to certain diving standards. "Green Fins," one of the largest of such initiatives, is an operator recognition program that requires its member dive centers to "promote a strict 'No Touch' policy for all reef diving and snorkeling" (Green Fins 2020a). Choosing to dive with "certified" dive centers can lead to significant reductions in reef contact rates (Camp and Fraser 2012; Hunt et al. 2013; Krieger and Chadwick 2013; Roche et al. 2016). However, in their current capacity, such programs lack sufficient incentive structures necessary for long-term compliance and remain largely localized. For example, while Green Fins may have had over 600 dive operator members across 11 countries since 2014 , only 143 of these dive centers were still active in 2020, most of which are concentrated in Southeast Asia (Green Fins 2020b).

A similar approach to reduce reef contacts is through voluntary dive standards. These diving guidelines are voluntary codes of conduct on how to reduce underwater environmental impacts, distributed by non-governmental organizations to conservation-minded divers and dive operators. The Coral Reef Alliance has a published list of voluntary standards for diving in the Mesoamerican Barrier Reef System, which informs divers to not "touch or contact corals or other reef dwelling organisms" (Coral Reef Alliance 2007). These guidelines are free for divers and dive operators to adopt, compliance is optional, and standards are often region specific. The Maui Reef Fund, a program initiated by the Hawai' $i$ Wildlife Fund, has a different set of standards for diving in Hawaii. These standards ask that divers and dive leaders "not handle marine life except on rare occasions" and to "look before touching the bottom for balance, making sure it is nonliving substrate" (Maui Reef Fund 2009). When different organizations promulgate inconsistent, non-binding standards across geographic regions, it can be difficult for divers to deviate from the prevailing status quo of high reef contact rates.

Specific approaches to reducing reef contacts recommended by many existing initiatives involve the use of instructional dive briefings and direct underwater interventions to discourage reef contacts. Pre- and post-dive briefings admonishing divers to reduce reef contacts range from having little to large success on reducing real-world contact rates (Medio et al. 1997; Barker and Roberts 2004), suggesting that the quality of instruction may be an important mediating variable (Camp and Fraser 2012). Inwater interventions involve dive leaders immediately bringing to attention any observed reef contacts made by divers during dives. These can significantly reduce reef contacts (Barker and Roberts 2004), but may be undermined when dive professionals themselves frequently make reef contact (Roche et al. 2016). 
The persistent rampancy of reef contacts suggests that, in isolation, voluntary approaches may not be adequate to properly address the reef contact problem. The prevalence of both intentional and unintentional contacts may be symptomatic of a diving culture that perceives reef contacts to be less of a conservation problem than they really are. If reef contacts are viewed as a small and inevitable side effect of diving, this likely propagates unsustainable expectations of what scuba diving entails and facilitates underwater social norms that subsequently excuse their occurrences. As such, viable long-term solutions will need to change the underlying structure of divers' attitudes toward reef contacts in order to better incentivize systemic, long-term compliance.

\section{Harnessing policy change for norm change}

The introduction of regulatory policies to reduce reef contacts can have positive, knock-on effects in facilitating an underwater social norm change. Social norms have varying definitions across disciplines, but generally comprise a constellation of predominant behaviors and attitudes toward what is acceptable within a group (Young 2015). Since human behaviors are often driven by conformity to other's expectations and behaviors, policies provide opportunities for people to change their beliefs toward what is considered acceptable behavior (Nyborg 2020). Once behavioral expectations are established, the share of norm followers increases in tandem with the strength of social sanctions against norm violators, and a self-reinforcing cycle of virtuous behavior change can ensue ( $\mathrm{Ny}-$ borg et al. 2016).

For example, following amendments to Norway's antismoking laws in 1988, the country saw widespread changes in attitudes toward smoking. While the law itself only prohibited smoking in certain public places (e.g., work premises and public transport), Norway saw wide-reaching effects on smoking norms even in places outside of the law's purview. Today, smoking in Norway almost never occurs indoors, including in previously unregulated spaces (e.g., private homes). This occurred despite limited governmental enforcement, driven predominantly by stricter social sanctions from non-smokers toward smokers. As anti-smoking laws led to less exposure to smoking in the general public, societal tolerance toward acts of public smoking also decreased, leading to even higher social sanctions and even less public smoking (Nyborg and Rege 2003). Similar examples of policy-driven social norm shifts include the prevalence of seat belt use following enforcement legislation in North America (Jonah 1984; James Hedlund et al. 2008), the abrupt end to female foot-binding in China (Mackie 1996), and the successful introduction of the uniform invoice lottery system to combat tax evasion in Taiwan (Fabbri and Hemels 2013).

The similar use of legislation to regulate reef contacts may help alter unsustainable underwater norms. Policies are especially poised to create tipping points of behavior change when adopting the behavior in question is (1) easily observable, (2) enjoys coordination benefits (a behavior is more readily practiced as it becomes more widespread), and (3) faces low compliance costs (Nyborg et al. 2016). Reef contacts (and their absence) are highly observable, as recreational diving is never done alone, and even unintentional or unnoticed contacts are equally visible to others. Coordination benefits also exist as reef contacts become less frequent. Recreational diving is done in buddy pairs, and divers are taught to always keep near to and at uniform depth with their dive buddies or dive group. Thus, divers maintaining a safe distance from the reef also impact their partners' behaviors, making stray reef contacts less likely for all. Further, as most divers care deeply about the world's coral reefs (Camp and Fraser 2012), social sanctions against reef contacts should rise as reef contacts become rarer, making divers less and less likely to make intentional contacts on a whim. Finally, foregoing reef contacts should also have relatively low compliance costs, since they are a by-product of diving and are by no means central to the sport's enjoyment. (In fact, reef contacts can be extremely painful, and contact with benthic marine life can even be deadly.)

\section{Leveraging marine protected area legislation}

Virtually all of the world's coral reefs open to recreational diving lie in territorial waters, within the exclusive economic zones (EEZs) of sovereign nations (UNCLOS 1982). This means that individual governments decide how best to handle coral reef tourism in their countries' respective EEZs. In line with existing marine conservation agendas, many countries choose to establish marine protected areas (MPAs) in their coastal waters that limit, to varying extents, the extraction, consumption, and use of reef resources. These MPAs are negotiated on a case-by-case basis, are often updated, and include regulations and allowances for recreational diving.

The existing legislative framework of MPAs provides policy-makers the opportunity to integrate additional reefprotecting policies into MPA legislation with relative ease and without the need for international treaties or extranational oversight. Such policies can be tailored to independently address both intentional and unintentional reef contacts, serving the dual purpose of directly reducing reef contacts in the places where they are in effect, and changing underwater norms that can impact divers' 
behaviors even in places where such policies are not yet in effect. The value of coral reefs to tourists is also closely aligned to their perceived ecosystem pristineness (Parsons and Thur 2008; Di Franco et al. 2009). Many divers also care about reef conservation, are aware that their underwater actions do damage to reefs, and even prefer more restrictive regulatory management than the current status quo (Sorice et al. 2007; Johnson and Jackson 2015). This suggests that effective and equitable policies to reduce damaging reef contacts also can benefit economic returns on tourism revenue and should be in the interest of both policy-makers and divers to pursue.

\section{Reducing intentional reef contacts}

MPA policies are easily configurable to reduce intentional reef contacts. By designating parts or all of MPAs open to recreational diving as "no-touch" zones, regulations can directly prohibit divers from making reef contacts at these sites. Observed and documented infractions would be open to formal sanctions (e.g., fines, permit suspensions, bans from subsequent visits, etc.), as imposed by marine park authorities (Cerutti-Pereyra et al. 2021). At face value, formal sanctions may defy enforcement, given the opacity of underwater behaviors to regulatory scrutiny and the often-limited resources of marine park authorities. However, social sanctioning can play a pivotal role in achieving desired behaviors, even in light of limited formal enforcement (Nyborg and Rege 2003). A legislative ban on reef contacts formally flags such behaviors as "wrong" and encourages divers to self-police and subsequently coursecorrect their behavior to avoid social sanctions associated with rule-breaking behavior. As reef contacts decrease in frequency, the perceived severity of subsequent contact events increases, leading to higher social sanctions and even fewer reef contacts. A "no-touch" policy may also incentivize divers to proactively correct for reef damages from unintentional collisions. Such measures might include diving a safe distance from the seabed, practicing proper buoyancy control, streamlining scuba equipment, and avoiding dives in difficult areas or under rough conditions.

\section{Reducing unintentional reef contacts}

Many unintentional reef contacts occur with trailing scuba equipment, like diving fins, and can occur entirely unnoticed by divers. A "no-touch" policy may not be entirely effective to guard against such occurrences, as it is difficult to regulate behaviors that occur outside of a diver's awareness or ability to control. To forestall unintentional contacts, the use of policy safeguards may be more effective. This could be an MPA regulation requiring divers to maintain a certain distance from the reef at all times, thereby creating a "safety bubble" above the reef to preempt lapses in buoyancy control or situational awareness that may otherwise result in accidental reef contact. However, such a safeguard policy may also increase compliance costs, especially for specialist divers. Underwater photographers, for instance, may need to sacrifice a certain level of intimacy with underwater subjects in order to comply with such rules. However, camera-carrying divers consistently make more reef contacts than noncamera divers (Harriott et al. 1997; Barker and Roberts 2004; Luna et al. 2009; Chung et al. 2013; Krieger and Chadwick 2013; Roche et al. 2016), while also valuing intact reefs more than do generalist divers (Anderson and Loomis 2011). This suggests that fair, well-implemented policy safeguards should be in the interest of all types of divers to enact and can lead to a better diving experience for all.

Other policy safeguards to reduce reef contacts may include stipulations on how large diving groups can be, what underwater conditions are permissible to dive under, and which types of finning techniques may or may not be used. Codes of conduct common in voluntary programs should also be better integrated into MPA regulations. These can include mandatory pre- and post-dive briefings admonishing divers to reduce reef contacts, and additional buoyancy control and environmental awareness training requirements to dive at certain sites.

\section{Promising policy precedents}

A handful of MPAs already have similar policies in place. In the Cabo Pulmo National Park in Baja California Sur, Mexico, divers are prohibited from swimming closer than $2.5 \mathrm{~m}$ to the reef (Baja Life Online 2005). For the most part, this policy has been well communicated, strictly enforced, and largely effective (Calderon-Aguilera, L. pers comm). In the last few decades, the park has also seen a concurrent revival of its fish biomass - the largest ecosystem recovery of any marine reserve (Aburto-Oropeza et al. 2011). Similarly, in Egypt, "touching corals and marine life is strictly prohibited" by the Egyptian Chamber of Diving and Water Sports, though the extent to which this policy is communicated to divers and diver operators remains uncertain (CDWS 2010). Analogously, in Taiwan, the touching of marine wildlife (e.g., sea turtles) is strictly prohibited and is periodically enforced under the country's Wildlife Conservation Act, though such regulations do not yet extend to cover reef contacts (Taiwan Council of Agriculture 1989). While promising, such policies remain either incomplete or noteworthy exceptions to the largely missed opportunity of harnessing regulatory action to minimize diver-reef interactions in MPAs. 
A more prevalent policy precedent has been the (successful) prohibition on glove use while diving in many tropical MPAs (e.g., Surin Islands Marine National Park, Thailand; Sharm El Sheikh, Egypt; and Cozumel Reefs National Park, Mexico). This supposedly discourages indiscriminate reef-touching by removing material protection from incidental abrasions, cuts, spines, or stings that might occur through reef-handling. In MPAs with such regulations, only extenuating medical circumstances, like a proneness to hypothermia or open wounds, serve as a viable reason for glove-wearing (STINAPA Bonaire 2006). Regardless of such a policy's net contribution to reef conservation, today, numerous divers dive without gloves, even in tropical regions where glove use is not prohibited. Other common conservation-oriented policy precedents in MPAs include stipulations for mooring line use in lieu of dive boats individually throwing anchor (Saphier and Hoffmann 2005; Giglio et al. 2017), and bans on dive knives or muck sticks (Baja Life Online 2005; CDWS 2010). Widespread compliance to these policies opens the door to more sweeping efforts to directly target reef contacts and better protect reefs from divers.

\section{Looking forward}

Reef-protecting policies are not a panacea to the reef contact problem. Formal enforcement will not be easy to implement, given limited resources of marine park authorities, and compliance will need to be largely driven by informal, social sanctions from within the dive community, plus the occasional prosecution. However, this has worked for other MPA policies (e.g., bans on glove use) and in other domains (e.g., the success of many public antismoking laws), suggesting that social sanctions following policy changes can drastically alter human behavior, even with limited formal enforcement (Nyborg and Rege 2003). Such policies should supplement, not supplant, existing conservation regulations and initiatives, and existing, provenly effective voluntary solutions should be expanded wherever possible. Indeed, such programs, like Green Fins, also work with local governments to strengthen national and regional regulations, laws, and policies, so their expansion could lead to beneficial outcomes in more than one domain (Harvey, C. pers comm).

Some sites may also benefit more from certain reefprotecting policies than others. For tourist hot spots of high conservation value or reefs particularly prone or sensitive to diver contacts (e.g., shallow reefs with many branching corals), for instance, a "safety bubble" approach mandating divers to keep a certain distance from the reef may be the best policy option. Such sites have much to gain from fewer damaging contacts, and relatively little to fear from compliance costs driving divers away. Other sites may not be tenable for "no-touch" policies at all, like sandy-bottom areas used for dive-certification training, or areas with heavy currents that require close reef-swimming or even reef hooks. Regulatory tools will need to be thoughtfully tailored to the situations and sites that will benefit most from their implementation, all while making sure to keep stakeholders adequately informed, involved, and onboard.

In short, regulatory bans on reef contacts or safeguard policies to a similar effect remain an underutilized tool to changing destructive diving norms and should be adopted wherever feasible. Voluntary approaches have been tried and tested, yet they have not reduced damages from diverreef contacts to a tolerable level. Perhaps it is time that topdown governance plays a more forceful role in facilitating behavior change. At the least, such policies can sustain and lend credibility to the admonishments of operator recognition programs, voluntary standards, scuba professionals, and diving peers to practice sustainable underwater behavior. At the most, affording coral reefs the additional protection of regulatory action can be the bold, yet pragmatic solution needed to permanently shift underwater norms for good.

Acknowledgements I would like to thank David Wilcove for the manuscript title, important edits, and invaluable mentorship; Fengyi Guo for a friendly review; Ryan Anderson, Luis Eduardo CalderonAguilera, Karine Nyborg, Chloe Harvey (The Reef-World Foundation), and Hannah Bernard (Hawai'i Wildlife Fund) for references and fact-checking correspondence; Michael Oppenheimer, Bryce Rudyk, Richard Stewart, Cassandra Emmons, and Elke Weber for course curricula that inspired the project's conception; and the High Meadows Foundation, Princeton University, and the Princeton University Library Open Access Fund for supporting my work.

\section{Declaration}

Conflict of interest The corresponding author states that there is no conflict of interest.

Open Access This article is licensed under a Creative Commons Attribution 4.0 International License, which permits use, sharing, adaptation, distribution and reproduction in any medium or format, as long as you give appropriate credit to the original author(s) and the source, provide a link to the Creative Commons licence, and indicate if changes were made. The images or other third party material in this article are included in the article's Creative Commons licence, unless indicated otherwise in a credit line to the material. If material is not included in the article's Creative Commons licence and your intended use is not permitted by statutory regulation or exceeds the permitted use, you will need to obtain permission directly from the copyright holder. To view a copy of this licence, visit http://creativecommons. org/licenses/by/4.0/. 


\section{References}

Aburto-Oropeza O, Erisman B, Galland GR, Mascareñas-Osorio I, Sala E, Ezcurra E (2011) Large recovery of fish biomass in a notake marine reserve. PLOS ONE 6:e23601

Anderson L, Loomis D (2011) SCUBA diver specialization and behavior norms at coral reefs. Coast Manag 39:478-491

Baja Life Online (2005) Cabo Pulmo National Park conservation program and management plan. http://www.cabopulmopark. com/rules.html

Barker NHL, Roberts CM (2004) Scuba diver behaviour and the management of diving impacts on coral reefs. Biol Conserv 120:481-489

Bellwood DR, Hughes TP, Folke C, Nyström M (2004) Confronting the coral reef crisis. Nature 429:827-833

Camp E, Fraser D (2012) Influence of conservation education dive briefings as a management tool on the timing and nature of recreational SCUBA diving impacts on coral reefs. Ocean Coast Manag 61:30-37

CDWS (2010) CDWS rules \& regulations. https://www.cdws.travel/ rules/General\%20Rules

Cerutti-Pereyra F, López-Ercilla I, Sánchez-Rivera G, Francisco V, Arvizu-Torres X, Adame-Sánchez T (2021) Impact of SCUBA divers on the coral reefs of a national park in the Mexican Caribbean. J Ecotourism 0:1-16

Chung S, Au A, Qiu J-W (2013) Understanding the underwater behaviour of scuba divers in Hong Kong. Environ Manage 51:824-837

Coral Reef Alliance (2007) Voluntary standards for marine recreation in the Mesoamerican reef system. 30

Di Franco A, Milazzo M, Baiata P, Tomasello A, Chemello R (2009) Scuba diver behaviour and its effects on the biota of a Mediterranean marine protected area. Environ Conserv 36:32-40

Fabbri M, Hemels S (2013) "Do you want a receipt?" Combating VAT and sales tax evasion with lottery tickets. pp. 430-443. https://doi.org/10.2139/ssrn.2232249

Giglio V, Ternes M, Mendes T, Cordeiro C, Ferreira C (2017) Anchoring damages to benthic organisms in a subtropical scuba dive hotspot. J Coast Conserv 21:311-316

Giglio VJ, Luiz OJ, Ferreira CEL (2020) Ecological impacts and management strategies for recreational diving: a review. J Environ Manage 256:109949

Gil MA, Renfro B, Figueroa-Zavala B, Penié I, Dunton KH (2015) Rapid tourism growth and declining coral reefs in Akumal, Mexico. Mar Biol 162:2225-2233

Green Fins (2020a) About Green Fins. https://www.greenfins.net/ about-green-fins

Green Fins (2020b) Green Fins members

Halpern BS, Walbridge S, Selkoe KA, Kappel CV, Micheli F, D'Agrosa C, Bruno JF, Casey KS, Ebert C, Fox HE, Fujita R, Heinemann D, Lenihan HS, Madin EMP, Perry MT, Selig ER, Spalding M, Steneck R, Watson R (2008) A global map of human impact on marine ecosystems. Science 319:948-952

Harriott VJ, Davis D, Banks SA (1997) Recreational diving and its impact in marine protected areas in Eastern Australia. Ambio 26:173-179

Hasler H, Ott JA (2008) Diving down the reefs? Intensive diving tourism threatens the reefs of the northern Red Sea. Mar Pollut Bull 56:1788-1794

Hawkins JP, Roberts CM (1992) Effects of recreational SCUBA diving on fore-reef slope communities of coral reefs. Biol Conserv 62:171-178

Hawkins JP, Roberts CM, Hof TV, Meyer KD, Tratalos J, Aldam C (1999) Effects of recreational scuba diving on Caribbean coral and fish communities. Conserv Biol 13:888-897
Hedlund J, Gilbert SH, Ledingham K, Preusser D (2008) How states achieve high seat belt use rates. 170

Hoegh-Guldberg O, Mumby PJ, Hooten AJ, Steneck RS, Greenfield P, Gomez E, Harvell CD, Sale PF, Edwards AJ, Caldeira K, Knowlton N, Eakin CM, Iglesias-Prieto R, Muthiga N, Bradbury RH, Dubi A, Hatziolos ME (2007) Coral reefs under rapid climate change and ocean acidification. Science 318:1737-1742

Hunt CV, Harvey JJ, Miller A, Johnson V, Phongsuwan N (2013) The Green Fins approach for monitoring and promoting environmentally sustainable scuba diving operations in South East Asia. Ocean Coast Manag 78:35-44

Johnson AE, Jackson JBC (2015) Fisher and diver perceptions of coral reef degradation and implications for sustainable management. Glob Ecol Conserv 3:890-899

Jonah BA (1984) Legislation and the prediction of reported seat belt use. J Appl Psychol 69:401-407

Krieger JR, Chadwick NE (2013) Recreational diving impacts and the use of pre-dive briefings as a management strategy on Florida coral reefs. J Coast Conserv 17:179-189

Lamb JB, True JD, Piromvaragorn S, Willis BL (2014) Scuba diving damage and intensity of tourist activities increases coral disease prevalence. Biol Conserv 178:88-96

Luna B, Pérez CV, Sánchez-Lizaso JL (2009) Benthic impacts of recreational divers in a Mediterranean Marine Protected Area. ICES J Mar Sci 66:517-523

Mackie G (1996) Ending footbinding and infibulation: a convention account. Am Sociol Rev 61:999-1017

Maui Reef Fund (2009) Voluntary standard for environmentally sustainable SCUBA diving practices in Hawaii

Medio D, Ormond RFG, Pearson M (1997) Effect of briefings on rates of damage to corals by scuba divers. Biol Conserv 79:91-95

Moberg F, Folke C (1999) Ecological goods and services of coral reef ecosystems. Ecol Econ 29:215-233

Nyborg K (2020) No man is an island: social coordination and the environment. Environ Resour Econ 76:177-193

Nyborg K, Rege M (2003) On social norms: the evolution of considerate smoking behavior. J Econ Behav Organ 52:323-340

Nyborg K, Anderies JM, Dannenberg A, Lindahl T, Schill C, Schluter M, Adger WN, Arrow KJ, Barrett S, Carpenter S, Chapin FS, Crepin A-S, Daily G, Ehrlich P, Folke C, Jager W, Kautsky N, Levin SA, Madsen OJ, Polasky S, Scheffer M, Walker B, Weber EU, Wilen J, Xepapadeas A, de Zeeuw A (2016) Social norms as solutions. Science 354:42-43

Ong TF, Musa G (2011) An examination of recreational divers' underwater behaviour by attitude-behaviour theories. Curr Issues Tour 14:779-795

PADI (2019) 2019 Worldwide Corporate Statistics

Parsons GR, Thur SM (2008) Valuing changes in the quality of coral reef ecosystems: a stated preference study of SCUBA diving in the Bonaire National Marine Park. Environ Resour Econ 40:593-608

Roche RC, Harvey CV, Harvey JJ, Kavanagh AP, McDonald M, Stein-Rostaing VR, Turner JR (2016) Recreational diving impacts on coral reefs and the adoption of environmentally responsible practices within the SCUBA diving industry. Environ Manage 58:107-116

Rouphael AB, Inglis GJ (1997) Impacts of recreational SCUBA diving at sites with different reef topographies. Biol Conserv $82: 329-336$

Saphier AD, Hoffmann TC (2005) Forecasting models to quantify three anthropogenic stresses on coral reefs from marine recreation: anchor damage, diver contact and copper emission from antifouling paint. Mar Pollut Bull 51:590-598

Sorice MG, Oh C-O, Ditton RB (2007) Managing scuba divers to meet ecological goals for coral reef conservation. AMBIO J Hum Environ 36:316-322 
Spalding M, Burke L, Wood SA, Ashpole J, Hutchison J, zu Ermgassen P (2017) Mapping the global value and distribution of coral reef tourism. Mar Policy 82:104-113

STINAPA Bonaire (2006) Bonaire National Marine Park: RULES AND REGULATIONS

Taiwan Council of Agriculture (1989) The Republic of China Wildlife Conservation Act

Toyoshima J, Nadaoka K (2015) Importance of environmental briefing and buoyancy control on reducing negative impacts of SCUBA diving on coral reefs. Ocean Coast Manag 116:20-26

Tratalos JA, Austin TJ (2001) Impacts of recreational SCUBA diving on coral communities of the Caribbean island of Grand Cayman. Biol Conserv 102:67-75

UNCLOS (1982) United Nations Convention on the Law of the Sea
Worachananant S, Carter RW (Bill), Hockings M, Reopanichkul P (2008) Managing the impacts of SCUBA divers on Thailand's coral reefs. J Sustain Tour 16:645-663

Young HP (2015) The evolution of social norms. Annu Rev Econ 7:359-387

Zakai D, Chadwick-Furman NE (2002) Impacts of intensive recreational diving on reef corals at Eilat, northern Red Sea. Biol Conserv 105:179-187

Publisher's Note Springer Nature remains neutral with regard to jurisdictional claims in published maps and institutional affiliations. 